\title{
Predictive maximal heart rate equations in child and adolescent athletes: a systematic review
}

\author{
Equações preditivas de frequência cardíaca máxima em \\ crianças e adolescentes atletas: uma revisão sistemática
}

Ecuaciones predictivas de frecuencia cardíaca máxima en
niños y adolescentes atletas: una revisión sistemática

Anderson Sartor Pedroni ${ }^{[a]}$, Aniuska Schiavo ${ }^{[a]}$, Eléia de Macedo ${ }^{[a]}$, Natália E de Campos ${ }^{[b]}$, Aline Dill Winck ${ }^{[a]}$, João Paulo Heinzmann-Filho ${ }^{[b]^{*}}$

[a] Universidade de Caxias do Sul (UCS), Caxias do Sul, RS, Brazil

[b] Pontifícia Universidade Católica do Rio Grande do Sul (PUCRS), Porto Alegre, RS, Brazil

\begin{abstract}
Introduction: The maximal heart rate (HRmax) is considered the highest value of HR achieved during a physical effort close to exhaustion. Objective: To evaluate the applicability of the predictive HRmax equations during exercise tests in child and adolescent athletes through a systematic review. Methods: It is a systematic review, through Scopus, Pubmed, Lilacs, Scielo and PEDro. The included studies compared the measured and estimated HRmax predictive equations during exercise tests in child and adolescent athletes. The following search strategy was used: "Exercise test OR Exercise testing OR Cardiopulmonary exercise test OR Cardiopulmonary exercise testing OR Peak
\end{abstract}

*ASP: undergrad, e-mail: aspedroni@msn.com ASP: undergrad, e-mail: aniuskashiavo@hotmail.com EM: MS, e-mail: eleiamacedo@yahoo.com.br NEC: Master's Student, e-mail: natiicampos@hotmail.com ADW: PhD, e-mail: alinelem@hotmail.com.br JHF: PhD, e-mail: joaopauloheinzmann@hotmail.com 
oxygen uptake OR Maximal oxygen consumption OR Exercise capacity OR Heart rate OR Heart rate OR Pulse rate OR Pulse rates OR Heart rate control OR Cardiac chronotropic OR Predictive value test AND Predictive equations". Results: From a total of 1,664 articles, only 4 were included. All compared the measured HRmax values with those estimated by the " 220 - age" equation; 3 used the formula " 208 - ( $0.7 \mathrm{x}$ age)", and only 1 used the " 223 - (1.44 x age)" equation. Although all of them stated that the "220 - age" equation overestimates HRmax, the formula "208 - (0.7 $\mathrm{x}$ age") underestimated ( 2 articles) and overestimated (1 study) the measured results, while the equation "213 (1.44 $\mathrm{x}$ age) was also not adequate. Conclusion: The use of predictive HRmax equations for child and adolescent athletes does not seem to be recommended. The use of cohort points for these estimates is carefully recommended.

Keywords: Heart Rate. Cardiovascular Physiology. Stress Test. Pediatrics.

\section{Resumo}

Introdução: A frequência cardíaca máxima (FCmáx) é denominada o maior valor de FC alcançada durante um esforço físico intenso. Objetivo: Avaliar a aplicabilidade das equações preditivas de FCmáx durante testes de exercício em crianças e adolescentes atletas. Métodos: Trata-se de uma revisão sistemática, através do Scopus, Pubmed, Lilacs, Scielo e PEDro. Foram incluídos estudos que compararam a FCmáx medida e a estimada por equações preditivas durante testes de exercício em crianças e adolescentes atletas. Utilizou-se a seguinte estratégia de busca: "Exercise test OR Exercise testing OR Cardiopulmonary exercise test OR Cardiopulmonary exercise testing OR Peak oxygen uptake OR Maximal oxygen consumption OR Exercise tolerance OR Exercise capacity AND Heart rate OR Heart rates OR Pulse rate OR Pulse rates OR Heart rate control OR Cardiac chronotropic OR Predictive value test AND Predictive equations". Resultados: De um total de 1664 artigos, apenas 4 foram incluídos. Todos os estudos compararam os valores medidos de FCmáx com os estimados pela equação "220 - idade", 3 utilizaram a fórmula "208- (0,7 x idade)" e apenas 1 a equação “223 - (1,44 x idade)". Embora todos demonstraram que a equação "220 - idade" superestima a FCmáx, a fórmula "208 (0,7 x idade") subestimou (2 artigos) e superestimou (1 estudo) os resultados medidos, enquanto a equação "213 - (1,44 $x$ idade) também não foi adequada. Conclusão: $O$ uso de equações preditivas de FCmáx em crianças e adolescentes atletas não parece indicado. Recomenda-se cuidadosamente a utilização de pontos de coorte para essas estimativas.

Palavras-chave: Frequência Cardíaca. Fisiologia Cardiovascular. Teste de Esforço. Pediatria.

\section{Resumen}

Introducción: La frecuencia cardiaca máxima (FCmáx) se denomina el mayor valor de FC alcanzado durante un esfuerzo físico cercano al agotamiento. Objetivo: Evaluar la aplicabilidad de las ecuaciones predictivas de FCmáx durante las pruebas de ejercicio en niños y adolescentes atletas. Métodos: Se trata de una revisión sistemática, a través del Scopus, Pubmed, Lilacs, Scielo y PEDro. Se incluyeron estudios que compararon la FCmáx medida y la estimada por ecuaciones predictivas durante pruebas de ejercicio en niños y adolescentes atletas. Se utilizó la siguiente estrategia de búsqueda: "Exercise test OR Exercise testing OR Cardiopulmonary exercise test OR Cardiopulmonary exercise testing OR Peak oxygen uptake OR Maximal oxygen consumption OR Exercise tolerance OR Exercise capacity AND Heart rate OR Heart rates OR Pulse rate OR Pulse rates OR Heart rate control OR Cardiac chronotropic OR Predictive value test AND Predictive equations". Resultados: De un total de 1664 artículos, sólo 4 fueron incluidos. Todos los estudios compararon los valores medidos de FCmáx con los estimados por la ecuación "220 - edad", 3 utilizaron la fórmula "208 - (0,7 x edad)" y sólo 1 la ecuación "223 - (1,44 x edad". Aunque todos demostraron que la ecuación "220 - edad" sobreestima la FCmáx, la fórmula "208 - (0,7 x edad") subestimó (2 artículos) y sobreestimó (1 estudio) los resultados medidos, mientras que la ecuación "213 - (1,44 $x$ edad) tampoco fue adecuada. Conclusión: El uso de ecuaciones predictivas de FCmáx en niños y adolescentes atletas no parece indicado. Se recomienda cuidadosamente el uso de puntos de cohorte para estas estimaciones.

Palabras clave: Frecuencia Cardíaca. Fisiología Cardiovascular. Prueba de Esfuerzo. Pediatría. 


\section{Introduction}

The heart rate (HR) is the number of times the heart contracts in one minute, demonstrating the work capacity needed to meet the body's metabolic demand during an activity [1 - 3]. This parameter increases linearly with exercise intensity and the maximal heart rate (HRmax) is the highest HR value achieved during a physical effort close to exhaustion $[4,5]$.

The HR is commonly used to verify cardiovascular response during effort and recovery after exercise [4, 6 - 9]. Athletes present better physical performance during exercise and HRmax values at rest may be lower in comparison to the group of sedentary individuals, as well as lower elevation at any level of exercise, and also present a faster return to the basal HR level after vigorous activities [10,11]. In addition, elevated HR at rest is considered an independent predictor of mortality in people with cardiovascular disease [2, 10, 12 - 14].

In the clinical routine, the HRmax can be used to verify the physical effort in ergometric or field tests, besides being used in the prescription of the intensity of aerobic exercises, considering its good relation with the maximal consumption of oxygen (VO2max) $[5,7,15,16]$.

The estimation of HRmax can be directly determined through incremental stress tests, or indirectly, through the use of predictive equations [5, 6, 17 - 20]. The predictive equations used to estimate HRmax are applied to all life cycles due to their convenience and ease of use, in addition to being variable formulas which decrease with age $[7,21$ 23]. This decrease is consensual among men and women, adults and the elderly. However, there is no consensus that this proposition is valid when applied to children and adolescents $[5,6,24]$, especially when dealing with athletes [25 - 28]. Furthermore, a recent research has shown that a cutoff point of $180 \mathrm{bpm}$ seems to be considered sufficient as maximal test, since the generated predictive equation in the pediatric sample had a low predictive power [29].

Therefore, considering that the generation of predictive equations is based on adult samples and that these formulas end up being extrapolated for the pediatric age group, it is necessary to investigate whether the application of these equations has good external validity or end up overestimating and / or underestimating the HRmax during the physical effort. Thus, we could avoid those individuals exceeding their physiological capacity and being subjected to inappropriate intensities of effort, with no aerobic increase. The objective of this study is to evaluate, through a systematic review, the applicability of the predictive HRmax equations used during exercise tests in child and adolescent athletes.

\section{Methods}

This study is a systematic review, carried out by searching the databases Scopus, Pubmed, Lilacs, Scielo and PEDro. The study was approved by the PROSPERO platform, under protocol number CRD42016049855 and carried out according to PRISMA guidelines [30]. Cross-sectional studies were selected in English and Portuguese, without filtering the year of publication and the language of origin of the studies. Data collection was performed in the period of March 2017.

For the selection of the articles, 16 descriptors were used, associated with the Boolean operators "AND" and "OR". The following search strategy was used: Exercise test OR Exercise testing OR Cardiopulmonary exercise test OR Cardiopulmonary exercise testing OR Peak oxygen uptake OR Maximal oxygen consumption OR Exercise tolerance OR Exercise capacity AND Heart rate OR Heart rates OR Pulse rate OR Pulse rates OR Heart rate control OR Cardiac chronotropic OR Predictive value test AND Predictive equations. These descriptors should be at least in the title, abstract or keywords. Furthermore, possible articles to compose the present work were investigated in the references of the studies included in this review (gray literature).

The inclusion criteria included studies with an observational design that compared the measured HRmax values obtained by maximal tests (HRmax > 180 bpm [sample mean]) [29] with the results estimated by predictive equations in child and adolescent athletes (aged up to 18). Moreover, it was chosen to include studies that showed at least the difference of HRmax (predicted by some predictive equations - measured value in the sample [called $\Delta]$ ]). The definition of athletes was based on the criteria of each author, including, any practice of sports activity. On the other hand, articles that evaluated HRmax in the non-athlete pediatric population, that only correlated measured HRmax data with values estimated by different predictive formulas (without disclosure of the above data), in addition to those using submaximal tests as well as literature review articles, letters to the reviewer and expert opinion were excluded from this study.

Two reviewers independently conducted the search and analysis of the articles and a third evaluator resolved the differences by consensus. After the identification of the descriptors in the title, abstract and / or keywords, 
the titles and abstracts were evaluated to assess the adequacy of the eligibility criteria.

The studies selected for the full reading were subsequently condensed into tables for better visualization of the data. The following data was extracted: name of the first author, year of publication of the study, country (origin) of the publication, age group, sample size, groups evaluated, test performed, protocol type, predictive equation, measured and estimated HRmax values and the main HRmax results.

The evaluation of the quality of the articles was carried out by the methodological evaluation scale and analyzed by two independent evaluators, with any divergence resolved in agreement with a third evaluator. An appropriate scale was used for observational studies by the Agency for Health Care Research and Quality (AHRQ) [31]. This instrument includes nine items related to the methodological aspects of the study, providing a total of 100 points. The studies were classified as low ( $<50$ points), moderate (50 - 66 points) and high ( $>66$ points) methodological quality.

\section{Results}

One thousand six hundred sixty-four articles were found: 917 in Scopus, 718 in Pubmed, 25 in Lilacs, four in Scielo and zero in PEDro. Of these, 1,662 articles were excluded because they did not meet the eligibility criteria for this review. In addition, other two articles were selected through gray literature. Thus, four studies comparing HRmax measured and estimated using different predictive equations in child and adolescent athletes were included. Figure 1 shows the flowchart regarding the total of articles found in the databases and the reasons of exclusion.

Figure 1 - Flowchart regarding the total of articles found in the databases and the reasons of exclusion.

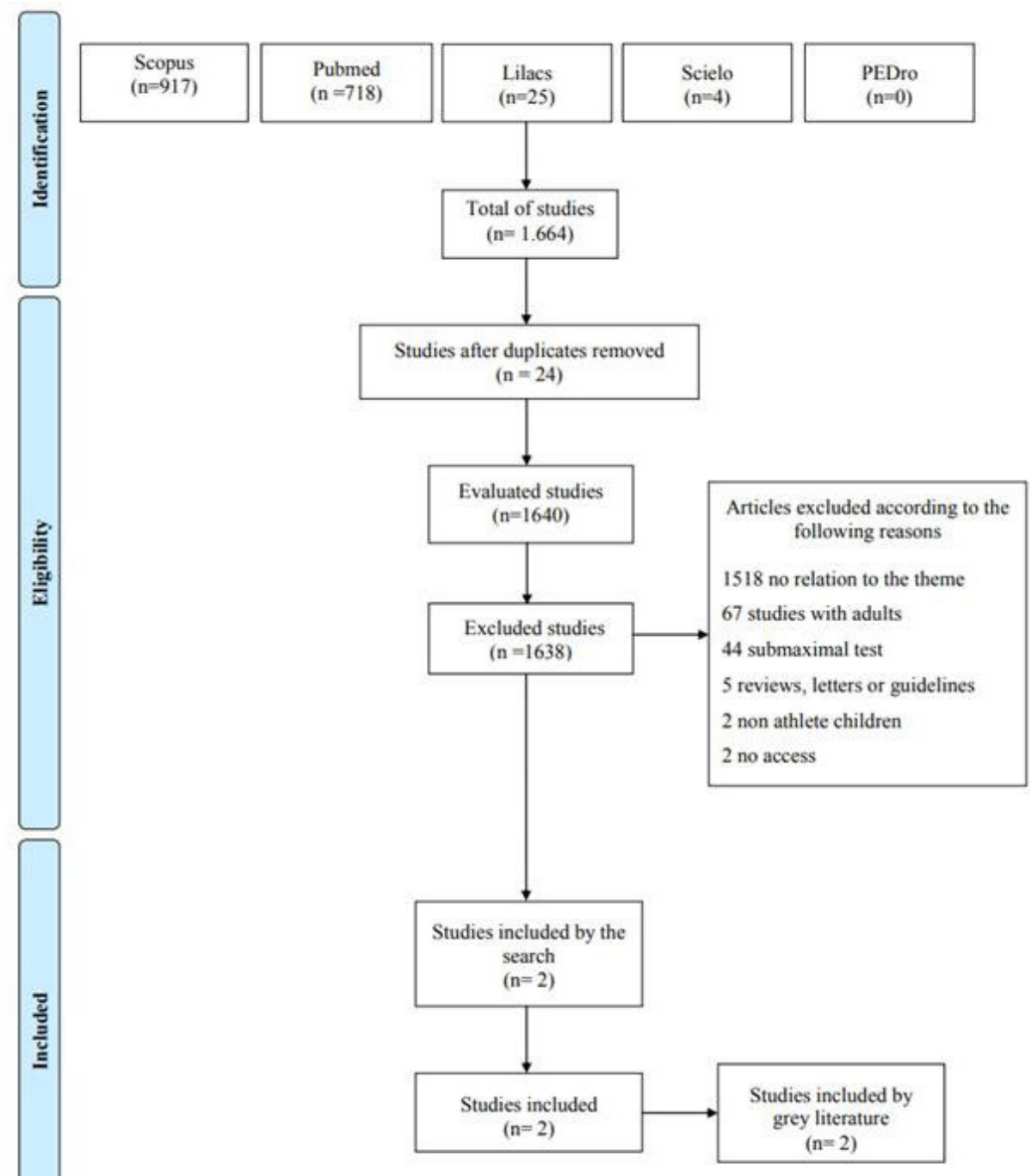


The sample size of the studies ranged from 23 to 158 individuals, totalizing 473 athletes. The age of the selected children and adolescents was 7 to 18 . From the four studies evaluated, two were conducted in Greece and two in Brazil, and half were soccer players. Table 1 shows with details the identification of the selected studies.
The Table 2 presents the characteristics and main results of the studies included in this review. Regarding the type of test performed to measure HRmax, one study performed the cardiopulmonary exercise test (CPET) using a treadmill, while three other articles used maximum field tests. Also, four analyzed the formula "220 - age", 3 used the equation "208 - (0.7 x age)" and one article analyzed the equation "223 - (1.44 x age)".

Table 1 - Identification and characteristics of the studies included in this review

\begin{tabular}{lcccc}
\hline First Author \& Year & Country & $\begin{array}{c}\text { Age group } \\
\text { (Years) }\end{array}$ & Sample & Evaluated groups \\
\hline Nikolaidis et al. 2015 (25) & Grece & $11-18^{*}$ & 158 & Soccer athletes \\
Nikolaidis et al. $2014(26)$ & Grece & $9-18$ & 147 & Soccer, futsal, basketball and water polo athletes \\
Colantonio et al. 2013 (27) & Brazil & $7-17$ & 145 & Athletes (swimmers) and non-athletes \\
Caputo et al.2012 (28) & Brazil & $12-14$ & 23 & Handball athletes \\
\hline
\end{tabular}

* It also included 162 adults in the sample (18 and 35 years of age). Data not shown.

Table 2 - Characteristics and main results of the studies included in this review.

\begin{tabular}{|c|c|c|c|c|c|}
\hline Firts author \& Year & $\begin{array}{c}\text { Test } \\
\text { performed }\end{array}$ & Protocol type & $\begin{array}{l}\text { Predictive } \\
\text { equations }\end{array}$ & HRmax value (bpm) & HRmax results \\
\hline $\begin{array}{l}\text { Nikolaidis et al. } \\
2015(25)\end{array}$ & $\begin{array}{l}\text { Modified } \\
\text { Conconi test }\end{array}$ & $\begin{array}{l}\text { Incremental } \\
\text { running test }\end{array}$ & $\begin{array}{c}\text { "220 - age" } \\
\text { "208 - (0.7 x age)" }\end{array}$ & $\begin{array}{l}\text { Measured: } 200.2 \pm 7.9 \\
\text { Estimated: } 204.2 \pm 1.5 \\
\text { Estimated: } 196.9 \pm 1.0\end{array}$ & $\begin{array}{l}\text { "220 - age" } \uparrow \text { and } \\
\text { "208 - (0.7 x age)" } \downarrow \\
\text { measured HRmax }\end{array}$ \\
\hline $\begin{array}{l}\text { Nikolaidis et al. } \\
2014(26)\end{array}$ & $\begin{array}{l}\text { Shuttle run } \\
\text { test }(20 \mathrm{~m})\end{array}$ & $\begin{array}{l}\text { Incremental } \\
\text { running test }\end{array}$ & $\begin{array}{c}\text { "220 - age" } \\
\text { "208 - (0.7 x age)" } \\
\text { "223 - (1.44 x age)" }\end{array}$ & $\begin{array}{l}\text { Measured: } 200.9 \pm 7.8 \\
\text { Estimated: } 206.4 \pm 2.5 \\
\text { Estimated: } 198.5 \pm 1.8 \\
\text { Estimated: } 203.4 \pm 3.7\end{array}$ & $\begin{array}{l}\text { “220 - age" and "223 } \\
\text { - (1.44 x age) " } \uparrow \text { and } \\
\text { "208 - (0.7 x age)" } \downarrow \\
\text { measured HRmax }\end{array}$ \\
\hline $\begin{array}{l}\text { Colantonio et al. } \\
2013(27)\end{array}$ & CPET & $\begin{array}{c}\text { Adapted Bruce } \\
\text { test }\end{array}$ & "220 - age" & $\begin{array}{c}\text { Measured: } \\
\text { 186.69 } \pm 13.26^{*} \\
\text { Estimated }+: \mathrm{N} / \mathrm{C}\end{array}$ & $\begin{array}{c}\text { "220 - age" } \uparrow \\
\text { measured HRmax }\end{array}$ \\
\hline $\begin{array}{l}\text { Caputo et al. } \\
2012(28)\end{array}$ & $\begin{array}{l}\text { Shuttle run } \\
\text { test }(20 \mathrm{~m})\end{array}$ & $\begin{array}{l}\text { Incremental } \\
\text { running test }\end{array}$ & $\begin{array}{c}\text { "220 - age" } \\
\text { "208 - (0.7 x age)" }\end{array}$ & $\begin{array}{l}\text { Measured: } 191.30 \pm 6.13 \\
\text { Estimated: } 206.80 \pm 0.79 \\
\text { Estimated: } 198.76 \pm 0.55\end{array}$ & $\begin{array}{c}\text { "220 - age" and } \\
\text { "208 - (0.7 x age)" } \uparrow \\
\text { measured HRmax }\end{array}$ \\
\hline
\end{tabular}

* Maximum heart rate (HRmax) data of boys in the athletes group (11-14 years of age); + : Article reports the HRmax difference (predicted value - measured value). Mean difference of $25.5 \pm 14.67$ (bpm) of the measured value in the sample; bpm: beats per minute; m: meters; $\mathrm{N} / \mathrm{C}$ : information not included in the article; CPET: cardiopulmonary exercise test; $\uparrow:$ overestimate; $\leftrightarrow$ : estimate properly; $\downarrow$ : underestimate.

All studies found that the "220 - age" equation overestimates the HRmax of children and adolescents. In contrast, the equation "208 - (0.7 x age)" seems to obtain conflicting results. In the latter equation, there was both underestimation (two studies) and overestimation (one study) of estimated HRmax. In addition, the predictive equation "223 - (1.44 x age)" tested in only one study overestimated the measured values of HRmax in this age group.

Finally, regarding the methodological quality of the selected articles, the average score was 78 points, with a variation between 76 and 80 , all classified as high methodological quality, according to the AHRQ scale (Table 3). 
Table 3 - Evaluation of the methodological quality of the studies included in this systematic review.

\begin{tabular}{lccccc}
\hline Criteria evaluated* & Reference Score & $\begin{array}{c}\text { Nikolaidis et al. } \\
2015(25)\end{array}$ & $\begin{array}{c}\text { Nikolaidis et al. } \\
2014(26)\end{array}$ & $\begin{array}{c}\text { Colantonio et al. } \\
2013(27)\end{array}$ & $\begin{array}{c}\text { Caputo et al } \\
2012(28)\end{array}$ \\
\hline Study question & $\mathbf{2}$ & 2 & 2 & 2 & 1 \\
Study population & $\mathbf{8}$ & 5 & 5 & 5 & 5 \\
$\begin{array}{l}\text { Comparability of individuals } \\
\text { for observational studies }\end{array}$ & $\mathbf{2 2}$ & 17 & 17 & 17 & 17 \\
Exposure or intervention & $\mathbf{1 1}$ & 11 & 11 & 11 & 11 \\
Measures of results & $\mathbf{2 0}$ & 20 & 20 & 20 & 20 \\
Statistical analysis & $\mathbf{1 9}$ & 12 & 12 & 10 & 14 \\
Results & $\mathbf{8}$ & 8 & 8 & 6 & 6 \\
Discussion & $\mathbf{5}$ & 5 & 5 & 5 & 5 \\
Financing and sponsorship & $\mathbf{5}$ & 0 & 0 & 0 & 0 \\
\hline Total score & $\mathbf{1 0 0}$ & 80 & 80 & 76 & 79 \\
\hline
\end{tabular}

*Some items on this scale did not apply directly to the study design. Thus, the studies ended up receiving scores on these criteria.

\section{Discussion}

HRmax is a parameter commonly used in the prescription of exercises to improve physical fitness and in monitoring the activity, seeking to achieve a safe approach. In this review, only four studies [25 - 28] which compared the measured HRmax of child and adolescent athletes were identified with the predicted values by three equations. Although there are several predictive equations of HRmax in the adult population [4, 32 - 35], these data are more restricted in the pediatric group, especially when it comes to athlete samples, which was evidenced in our review [25 - 28].

From the physiological point of view, sports practice, be it swimming, handball, basketball and / or soccer, causes cardiovascular adaptations in the trained individual. Athletes classically have lower HRmax scores at rest, at the peak physical exercise and a rapid recovery of the heart pump after intense activity, when compared to sedentary individuals. This fact occurs because athletes undergo some cardiovascular adjustments, such as increased blood flow to the muscles during physical activities due to increased local metabolic need, with consequent increase in oxygen consumption $[10,11]$. Thus, since most of the tested equations ("220-age" and "208 $(0.7 \mathrm{x}$ age $) ")[33,34]$ were generated from adult and non-athlete subjects, it is believed that it may explain the negative results found for the applicability of these equations in the infant sample.

Our data suggest that the "220-age" equation should not be used to estimate the HRmax for child and adolescent athletes, considering that all included studies [25 - 28] showed an overestimation of this variable in relation to that measured in the samples. Classically, the "220 - age" equation is often cited in exercise physiology books and articles, as well as in sports medicine exams and fitness programs [32]. However, a surprising fact is that this formula has unknown authorship, and is often attributed to different authors $[32,33]$. The inquiry into the history of this formula reveals that it was not developed from an original research, but rather from observation of data based on approximately 11 unpublished scientific references or compilations [32,33]. Furthermore, it seems that this equation was generated from a sample composed of subjects with chronic diseases and smokers, which in fact does not represent the reality of the pediatric athletic population $[32,33]$.

The present study also showed an inadequacy of the formula "208 - (0.7 x age)" when applied to the pediatric sample, obtaining estimated values above the measured in one [28] and in two studies below the measured [25, 26]. Tanaka et al. [34] proposed such equation, which was generated from a meta-analysis that included data from 18,712 subjects, ranging from 20 to 90 years of age. An interesting fact is that this predictive formula was able to explain about $80 \%$ of the HRmax variability of 
the adults evaluated. Although Caputo et al. [28] showed an overestimation of the equation "208 - (0.7x age) in his small sample of 23 handball athletes, the studies of Nikolaidis et al. [25, 26] observed underestimation ( 2.4 and 3.3 beats per minute) of the predicted HRmax compared to the values measured in the samples. From a practical point of view, this small underestimation of the studies by Nikolaidis et al. $[25,26]$ does not seem to cause as many problems in HRmax estimation, considering that the subjects exceeded the predicted HR values, which would also indicate a maximum test. However, from the statistical point of view they have inadequately estimated the use of this formula, so it is not recommended either.

Only one study compared the equation " 223 - (1.44x age)" with the measured values of HRmax in its sample [26]. This work stands out from the other predictive formulas, since it generated HRmax equations on samples composed of both adolescents and adults. Another differential of this research was the fact that the authors disclosed equations separately according to the investigated age group, which could facilitate its applicability in clinical practice. Nevertheless, even using a specific formula for the age group, when applied in another study of the same research group, it ended up overestimating the results of HRmax [26]. This fact could be attributed to the study by Nikoladis et al. [26], which included subjects with slightly different sample characteristics, including younger individuals as well as athletes with different sports modalities. In this context, another study [29] composed of 433 child and adolescent athletes proposed to generate a new predictive HRmax equation. However, in addition to the low predictive power of the generated formula, which ended up including resting HR, physical fitness level, body mass index and fat percentage, the age did not influence the proposed model. Thus, the authors recommend the use of minimum cohort points (180 $\mathrm{bpm}$ ) as a criterion of maximum physical effort in this population [29]. This result seems to corroborate some previous data in the pediatric population, indicating that age does not directly influence the HRmax of this age group, which could be justified due to the different chronotropic effects and the weak correlation between age and HRmax in youngsters [7, 35 - 37]. In addition, it seems that the use of fixed cohort points could be a viable alternative for its application in this sample, considering that no predictive equation seems to be adequate up to now.

From the total of four articles, three $[25,26,28]$ used field tests (shuttle run test and the modified Conconi protocol) and only one [27] used CPET (adapted Bruce) for measurement of HRmax in their samples. Although these studies differed from the choice of the test, both used ramp protocol evaluations, based on velocity and / or inclination increments. According to Almeida et al. [37], the use of ramp protocols favors HR observation throughout the test, with progressive and linear increases until HRmax is achieved. Previous data in the literature also have confirmed these aspects, suggesting that field tests with such characteristics of speed and increments can lead children and adolescents to physical exhaustion, very similar to the tests performed on ergometers [38 - 40]. One point that deserves to be highlighted is the fact that our initial proposal was only to include articles that had assessed HRmax in child and adolescent athletes by ergometers because, classically, they are maximal tests. However, based on the shortage of studies in the pediatric age group and because the field tests included in this review seem to be maximum (mean HRmax > $180 \mathrm{bpm}$ in the samples) $[25,26,28]$, it was decided to keep them in our study.

\section{Conclusion}

The findings of this review demonstrate that the application of different predictive HRmax equations for child and adolescent athletes should be avoided, considering the findings of underestimation and overestimation of the results. In addition, although the "220-age" equation is widely used to estimate HRmax in adults, its use in the athletic infant sample may generate biases in the estimation of physical effort.

Other studies should be conducted to evaluate other possible predictive variables of HRmax, including rest $\mathrm{HR}$, fat percentage, body mass index, physical fitness, among others. Moreover, the use of fixed cohort points in this portion of the population may be a viable alternative to estimate HRmax. However, these cohort points need to be extensively tested, considering their good application to the athletic pediatric population tested up to now. 


\section{Acknowledgment}

The authors (NEC and JPHF) thank CNPq and CAPES for granting aid grants.

\section{References}

1. de Souza EG, Istchuk LL, Lopez JA, da Silva KA, de Almeida Batista L, Gonçalves HR, et al. Comparação entre frequência cardíaca máxima predita e mensurada em atletas adolescentes de Futsal. Rev Bras Futsal e Futebol. 2016;7(26):455-9.

2. Caetano J, Delgado Alves J. Heart rate and cardiovascular protection. Eur J Intern Med. 2015;26(4):217-22.

3. Hui SS, Chan JW. The relationship between heart rate reserve and oxygen uptake reserve in children and adolescents. Res Q Exerc Sport. 2006;77(1):41-9.

4. Silva VA, Bottaro M, Justino MA, Ribeiro MM, Lima RM, Oliveira RJ. Maximum heart rate in Brazilian elderly women: comparing measured and predicted values. Arq Bras Cardiol. 2007;88(3):314-20.

5. Camarda SR, Tebexreni AS, Páfaro CN, Sasai FB, Tambeiro VL, Juliano Y, et al. Comparison of maximal heart rate using the prediction equations proposed by Karvonen and Tanaka. Arq Bras Cardiol. 2008;91(5):311-4.

6. Pereira-Rodríguez J, Boada-Morales L, Jaimes-Martin T, Melo-Ascanio J, Niño-Serrato D, Rincón-González G. Predictive equations for maximum heart rate. Myth or reality. Rev Mex Cardiol. 2016;27(4):156-65.

7. Machado FA, Denadai BS. Validity of maximum heart rate prediction equations for children and adolescents. Arq Bras Cardiol. 2011;97(2):136-40.

8. Bendiksen M, Williams CA, Hornstrup T, Clausen H, Kloppenborg J, Shumikhin D, et al. Heart rate response and fitness effects of various types of physical education for 8- to 9-year-old schoolchildren. Eur J Sport Sci. 2014;14(8):861-9.

9. Hiilloskorpi HK, Pasanen ME, Fogelholm MG, Laukkanen RM, Mänttäri AT. Use of heart rate to predict energy expenditure from low to high activity levels. Int J Sports Med. 2003;24(5):332-6.

10. Cook S, Togni M, Schaub MC, Wenaweser P, Hess OM. High heart rate: a cardiovascular risk factor? Eur Heart J. 2006;27(20):2387-93.
11. Achten J, Jeukendrup AE. Heart rate monitoring: applications and limitations. Sports Med. 2003;33(7):517-38.

12. Dhoble A, Lahr BD, Allison TG, Kopecky SL. Cardiopulmonary fitness and heart rate recovery as predictors of mortality in a referral population. J Am Heart Assoc. 2014;3(2):e000559.

13. Pittaras AM, Faselis C, Doumas M, Myers J, Kheirbek $\mathrm{R}$, Kokkinos JP, et al. Heart rate at rest, exercise capacity, and mortality risk in veterans. Am J Cardiol. 2013;112(10):1605-9.

14. Jouven X, Empana JP, Escolano S, Buyck JF, Tafflet M, Desnos $\mathrm{M}$, et al. Relation of heart rate at rest and longterm ( $>20$ years) death rate in initially healthy middleaged men. Am J Cardiol. 2009;103(2):279-83.

15. Vasconcelos TL. Comparação das respostas de frequência cardíaca máxima através de equações preditivas e teste máximo em laboratório. Rev Bras Presc Fisiol Exerc. 2011;1(2):19-24.

16. Guazzi M, Arena R, Halle M, Piepoli MF, Myers J, Lavie CJ. 2016 focused update: clinical recommendations for cardiopulmonary exercise testing data assessment in specific patient populations. Eur Heart J. 2018;39(14):1144-1161. doi: 10.1093/eurheartj/ ehw180.

17. American Thoracic Society; American College of Chest Physicians. Statement on cardiopulmonary exercise testing. Am J Respir Crit Care Med. 2003;167(2):211-77.

18. Jakicic JM, Donnelly JE, Pronk NP, Jawad AF, Jacobsen DJ. Prescription of exercise intensity for the obese patient: the relationship between heart rate, VO2 and perceived exertion. Int J Obes Relat Metab Disord. 1995;19(6):382-7.

19. Balogun MO, Ladipo GO. Cardiovascular responses to maximal treadmill exercise in healthy adult Nigerians. Afr J Med Med Sci. 1989;18(2):109-16.

20. Prado DM, Braga AM, Rondon MU, Azevedo LF, Matos LD, Negrão CE, et al. [Cardiorespiratory responses during progressive maximal exercise test in healthy children]. Arq Bras Cardiol. 2010;94(4):493-9.

21. Christou DD, Seals DR. Decreased maximal heart rate with aging is related to reduced \{beta\}-adrenergic responsiveness but is largely explained by a reduction in intrinsic heart rate. J Appl Physiol (1985). 2008;105(1):24-9. 
22. de Oliveira Segundo VH, de Albuquerque NJB, Matos F, Dantas PMS, Pinto EF. Use of predictive equations of maximum heart rate for exercise prescription: a comparative study. IOSR. 2016;3(1):4-8.

23. Ozemek C, Whaley MH, Finch WH, Kaminsky LA. Maximal heart rate declines linearly with age independent of cardiorespiratory fitness levels. Eur J Sport Sci. 2017;17(5):563-70.

24. Verschuren O, Maltais DB, Takken T. The 220-age equation does not predict maximum heart rate in children and adolescents. Dev Med Child Neurol. 2011;53(9):861-4.

25. Nikolaidis PT. Maximal heart rate in soccer players: measured versus age-predicted. Biomedical J. 2015;38(1):84-9.

26. Nikolaidis PT. Age-predicted vs. measured maximal heart rate in young team sport athletes. Niger Med J. 2014;55(4):314-20.

27. Colantonio E, Kiss M. Is the HRmax= 220-age equation valid to prescribe exercise training in children. J Exerc Physiol Online. 2013;16(1):19-27.

28. Caputo EL, da Silva MC, Rombaldi A. Comparação da frequência cardíaca máxima obtida por diferentes métodos. J Phys Educ. 2012;23(2):277-84.

29. Gelbart M, Ziv-Baran T, Williams CA, Yarom Y, DubnovRaz G. Prediction of Maximal Heart Rate in Children and Adolescents. Clin J Sport Med. 2017;27(2):139-44.

30. Liberati A, Altman DG, Tetzlaff J, Mulrow C, Gøtzsche PC, Ioannidis JP, et al. The PRISMA statement for reporting systematic reviews and meta-analyses of studies that evaluate health care interventions: explanation and elaboration. Plos Med. 2009; 21;6(7):1-28

31. West S, King V, Carey TS, Lohr KN, McKoy N, Sutton SF, et al. Systems to rate the strength of scientific evidence. Evid Rep Technol Assess (Summ). 2002(47):1-11.

32. Robergs RA, Landwehr R. The surprising history of the "HRmax= 220-age" equation. J Exerc Physiol. 2002;5(2):1-10.
33. Fox SM, Naughton JP, Haskell WL. Physical activity and the prevention of coronary heart disease. Ann Clin Res. 1971;3(6):404-32.

34. Tanaka H, Monahan KD, Seals DR. Age-predicted maximal heart rate revisited. J Am Coll Cardiol. 2001;37(1):153-6.

35. Barbosa e Silva O, Saraiva LC, Sobral Filho DC. Treadmill stress test in children and adolescents: higher tolerance on exertion with ramp protocol. Arq Bras Cardiol. 2007;89(6):391-7.

36. Mahon AD, Marjerrison AD, Lee JD, Woodruff ME, Hanna LE. Evaluating the prediction of maximal heart rate in children and adolescents. Res Q Exerc Sport. 2010;81(4):466-71.

37. de Almeida MB, Ricardo DR, de Araújo CGS. Variabilidade da frequência cardíaca em um teste de exercício verdadeiramente máximo. Revista da SOCERJ. 2005.

38. Quinart S, Mougin F, Simon-Rigaud ML, Nicolet-Guénat $M$, Nègre V, Regnard J. Evaluation of cardiorespiratory fitness using three field tests in obese adolescents: validity, sensitivity and prediction of peak V02. J Sci Med Sport;17(5):521-5.

39. Gomes EL, Sampaio LM, Costa IP, Dias FD, Ferneda VS, Silva GA, et al. Analysis of autonomic modulation during maximal and submaximal work rate and functional capacity in asthmatic children. J Asthma. 2013;50(6):613-8.

40. Solway S, Brooks D, Lacasse Y, Thomas S. A qualitative systematic overview of the measurement properties of functional walk tests used in the cardiorespiratory domain. Chest. 2001 Jan;119(1):256-70.

Received in 09/22/2017 Recebido em 22/09/2017 Recibido en 22/09/2017

Approved in 05/24/2018 Aprovado em 24/05/2018 Aprobado en 24/05/2018 